\title{
EnHancement OF TEACHING TeChNiQUES AND STUDENT Learning in a Production Technology Undergraduate Course
}

\author{
A. Mohamed, A. Fisher, and G. F. Naterer \\ Faculty of Engineering and Applied Science, Memorial University, St. John's, NL, AlB $3 X 5$ \\ amohamed@mun.ca
}

\begin{abstract}
Engineering education requires engineering practice, supervision, and experience. This paper examines some of the main elements of engineering education and its challenges in mechanical and manufacturing engineering courses. Innovative teaching and learning methods are discussed for introducing students to the engineering profession.

A number of techniques and suggestions are provided to enhance the engineering education process. These include the importance of practice, audio-visual tools, and broadening the students' perspectives of ethical issues in engineering.

Student feedback indicates that such an integrated approach enhances their learning. Industrybased projects help them to be better prepared for the graduate engineering profession as well as improve their communication skills. A number of such enhancements to engineering courses are highlighted in this paper.
\end{abstract}

Keywords: machine shop, production technology, quizzes, teaching, learning, student group, assignment

\section{INTRODUCTION}

Awareness and understanding of teaching and optimal learning modes of undergraduate engineering students by both engineering students and instructors are important for providing meaningful and effective teaching and learning experiences. Effective teaching and learning techniques are established by understanding how engineering students learn [1]. There is a close link between teaching and learning. The recognition that engineering students learn in different ways is important and they may not always find themselves in an effective learning environment in a classroom that considers and incorporates variety into teaching. Mismatches between teaching and learning techniques [2], are among several factors that contribute to ineffective teaching and learning techniques in the engineering classroom. However, given the uniqueness of individuals and the diversity and complexity of learning needs, the provision of absolute matching of learning techniques to teaching techniques may not always be achieved. However, efforts should be made to provide more effective learning experiences of the engineering profession in the classroom.

According to Brent [3], various teaching and learning techniques have their own characteristic way of providing, taking in, and processing information with students. One learning technique is neither preferable nor inferior to another, but is simply different, with different characteristic strengths and weaknesses. Engineering students are typically exposed to different types of information, for example, lecture presentations based on PowerPoint, audio-visual, hands on experiments, small group practice or exercise. Several researchers $[4,5]$ stated that students whose learning techniques are compatible with the teaching technique of a course instructor tend to remember information longer, apply it more effectively, and have more positive post-course attitudes toward the subject than their counterparts who experience a teaching and learning technique mismatch.

\section{TEACHING TECHNIQUES}

Teaching techniques can be classified into three categories - traditional, reverse, and facilitative teaching.

\subsection{Traditional Techniques}

The most prevalent form of teaching occurs where the instructor is the center. Despite its popularity, it is the least effective learning process. It was reported $[6,7]$ that students remember about $70 \%$ of the first 10 minutes of content, but only $20 \%$ of the last 10 minutes. Students are not as likely to be actively engaged in this type of learning, given the one-way flow of information, and therefore less likely to benefit. It is still the most common teaching technique used by instructors, especially those instructors who do not have the confidence to change from this teaching technique to another, or may not feel confident in covering the course content on time if they switch to a different teaching technique. There are also 
some facts and theories in engineering where instructors are encouraged to deliver lectures in a one-way flow.

\subsection{Reverse Techniques}

The reverse technique is highly suitable for the teaching of engineering. In the theory of constructivism $[8,9]$, the student is at the center of the learning process, and from this position develops his/her understanding of the way that the engineering world works. The focus of such classroom learning is on concept development and thorough understanding. It requires a reorganization of teaching format [8, 10]. For example, by using this method in the teaching of material manufacturing processes, a student's retention of content material can be substantially improved. The instructor guides the students to discover the abstract content, such as principles, theories and concepts, by using the Kolb [11] learning cycle of providing examples and asking questions. The process moves smoothly from specific, concrete examples to the abstract. For instance, the instructor begins with simple examples that students understand and can discuss.

The students are then encouraged to gradually build or develop the theory or concept that is being taught. Once students discover and understand the abstract concept, the instructor can proceed by traditional teaching. This practical way of combining traditional and reverse teaching techniques has the potential to be an efficient way of teaching engineering.

\subsection{Facilitative Techniques}

Facilitative teaching requires the instructor to become the supervisor. The instructor supervises the discussion while the students generate the content. Students are more engaged in this process and tend to feel more ownership of their learning process as compared to traditional teaching; discussion and content retention increase substantially in comparison to lectures alone [6]. Although very effective, this type of teaching technique is, however, more challenging to adapt to the engineering classroom because engineering education requires the learning of significant amounts of technical information, which often precludes the use of the discussion technique. However, this technique could be used in a few situations to create interaction between students in the class and to help them express their understanding of a subject. Also, for the instructor, this technique reveals different capabilities and oral communication skills of the students. For the most effective teaching in the engineering classroom, the instructor should apply all three techniques as appropriate.

\section{LEARNING TECHNIQUES}

Learning is a continuous process of acquiring knowledge and information, which leads to growth of science and engineering technology $[4,12]$. The purposes of most teaching and learning techniques are to motivate and encourage the desire to learn, to develop skills for looking for new, novel and creative ideas for solving engineering problems, and to move towards engineering students becoming professionals in real world problemsolving. The fulfillment of these goals is essential in the education of engineering students in the classroom. But if instructors in engineering institutions are not effectively planning to meet these goals through the use of appropriate teaching and learning techniques, then there is room for improvement on how engineers are trained.

This paper is based on a specific course, taught by the first author of this paper in which some techniques for teaching and learning in the classroom and engineering practice in the real-world are presented. It is anticipated that these observations can be extended to other advanced engineering courses in order to raise awareness of students' learning techniques.

\section{METHODOLOGY}

Production Technology ENGI 3941 is an undergraduate course at Memorial University which consists of three 50-minute classes and two hours of practice in the machine shop per week over twelve weeks.

The course background includes a brief study of machining operations, material properties, measurement, inspection and testing, casting, forming, material removal and joining processes. The instructor (first author) modified the Biggs [6] method and employed it in the classroom with practice by discovery, practice by exercise, and practice by doing, as shown in Fig.1.

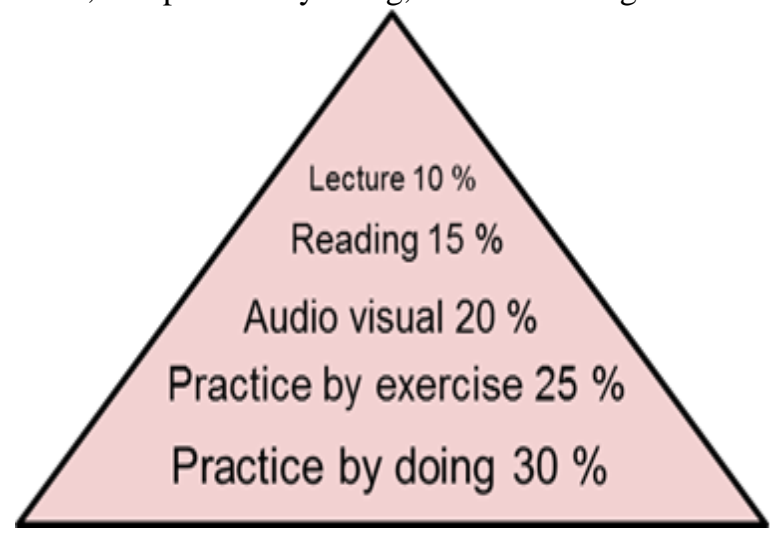

Fig. 1. Increasing student learning a result of teaching techniques (adapted from [6]). 


\subsection{Practice By Audio-Visual}

If "a picture is worth a thousand words", then a video is worth a million. Engineering and science topics from the specialty Discovery Channel as shown in Fig. 2 have been adopted and employed in the classroom by the instructor as an effective learning tool for the last 10 minutes of each lecture. For example, for the lecture on bulk deformation processes (forging, rolling), the video component provides a brief account of forging and rolling. In another example, for the lecture topic of advanced alloys used in jet engine blades because of their high strength, creep and corrosion resistance, and impact loading and fracture properties, students watch a short video about the Titanic ship. In these lectures, the four quadrants of the Kolb [11] learning cycle are used: Why? What? How? What if? From a Discovery Channel video on one of the most catastrophic airline accidents in 1988, an Aloha Airlines Boeing 737, the students also learned about the air crash investigation.

These experiences engage students with real world engineering problems in which they learn from highly experienced and internationally recognized professional engineers dealing with serious failures of engineering systems.

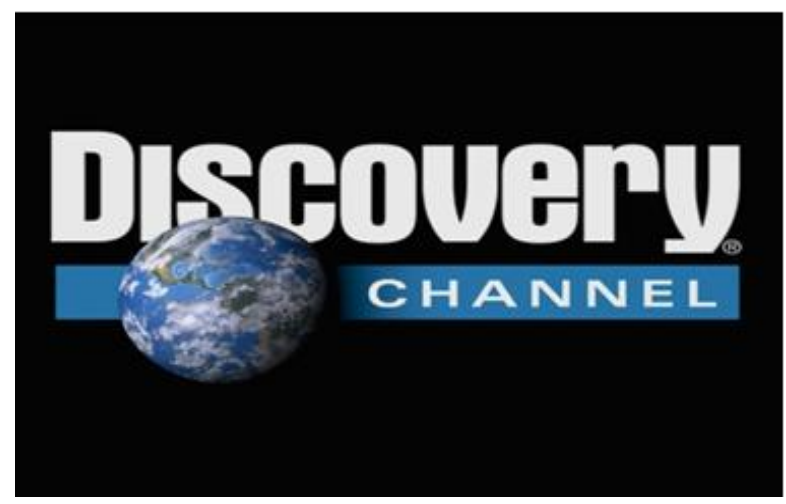

Fig. 2. Topics from the specialty Discovery Channel adopted and employed in the classroom

A study carried out by Stice [13] concluded that students retain $10 \%$ of what they read, $26 \%$ of what they hear, $30 \%$ of what they see, $50 \%$ of what they see and hear, $70 \%$ of what they say, and $90 \%$ of what they say as they do something.

\subsection{Practice By Exercise}

The first author has used "practice by exercise" in a course by developing a set of six to eight biweekly quizzes and two major assignments to test the students' understanding of the objectives of the lecture topics covered. Both these activities are not part of the course mark distribution so no marks are given for quizzes and assignments. In the first assignment, student groups read the topics assigned by the instructor where they will be examined for the midterm exam and each group is requested to develop three questions. These questions should not be copied from textbook questions. Answer keys are developed for each question. The first question had to follow a true-false format for assessing a simple recall of factual information. Question two had a multiple choice format, and for question three, a fill in the blank and matching exercise was given. The instructor requested a fixed question format for consistency among the groups.

A deadline for submitting the assignment by e-mail was set and all the questions collated in one package as for an exam, This paper was handed to students as homework to answer the questions and provide feedback regarding the question structure or answer keys. A date was set before the midterm exam for finalizing the answers together with students in the classroom. For the second assignment, the same procedure was used except that student groups were requested to read and develop three questions from lecture topics from reading materials assigned after the midterm to the final exam. With 20 groups, some 60 questions were generated and used as a review tool prior to the exams. None of the questions were used directly in the exams. Since student groups had ownership of the questions, they were taught team spirit, leadership, better organizing abilities, and had a greater interest in and better comprehension of the subject.

The set of six to eight bi-weekly individual and occasional group quizzes were given throughout the term to test student knowledge of basic design issues and scientific nomenclature, to help in improving retention and to promote active learning through integrative reasoning. All these learning experiences helped in improving intellectual power. The quizzes were developed in such a way as to cover all topics in the course, reinforce the key concepts, and to better understand the objectives of each topic.

Working in small groups is an essential element of a successful teaching-learning environment, promotes cooperative learning skills and facilitates student interactions that allow students with engineering experience and knowledge in specific areas to share with one another. Students were very enthusiastic about this practice, became more confident, and exhibited a higher level of personal ownership for their learning in the early years of the engineering program. The current study supports a past study by Johnson [14] which found that students often respond negatively to group work at first, with the benefits of the approach only fully realized when the group work is structured in such a way as to elicit positive interdependence, individual accountability, and appropriate use of team work and interpersonal skills. 
This exercise-based assignment provided an opportunity for students to interact through the sets of questions that they developed. Also, it gave an opportunity for the instructor to discover the ways in which students were understanding and perceiving the course and its concepts and how they were thinking about the course. It also gave the opportunity for students to express their ideas and talents by developing their own questions.

\subsection{Practice By Doing}

Prior to any activity in the machine shop, students in the classroom are required to became familiar with machine shop safety practices and operation of shop equipment, including the vertical mill, lathe, drill press, cut-off saw, drill presses and related equipment available in the machine shop lab such as shown in Fig. 3.

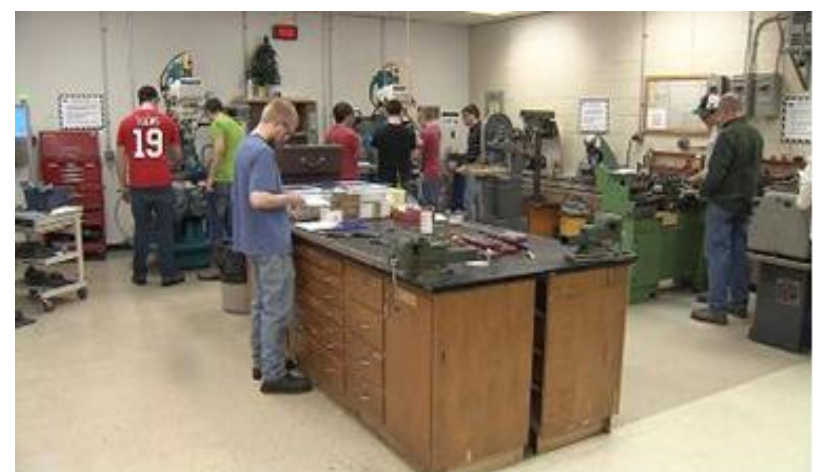

Fig. 3. Students in the machine shop lab fabricate parts of a Stirling engine project

Students participated in a project to fabricate and produce a Stirling Engine-Closed Engine in which they used a variety of machine shop equipment and best practices. Students were familiarized with safe machine operation and set-up before starting any activity. In addition, an emphasis was put on fostering independent thinking in coming to an understanding of sizing of tap drills, identifying screw threads, inspection and quality control, shop charts, machine speeds, feeds, and other related shop material.

The students were made aware of how to analyze problems they might encounter in machining engine parts. For example, students were able to practice and verify the crucial importance of allowances and tolerances in machining and fabrication process. The practice and skills allowed students to analyze problems from an optimization perspective and provided them with background knowledge of what is involved in later courses. Students found the machine shop labs not only provide valuable learning experiences but found them enjoyable and rewarding.
In the last two weeks of a term, once students had machined all of the engine parts required such as shown in Table 1, they were given a list of steps to assist with assembling a Stirling Engine-Closed Engine such as that shown in Fig. 4. Much care was considered for assembly and parts so they fit very well together. For example, the power piston and cylinder fit close enough to create a seal but without causing friction during movement. A test to confirm Stirling engine work and run it continuously with power of a small propane cylinder is shown in Fig. 5.

Table 1: List of engine parts and their materials

\begin{tabular}{|l|l|l|}
\hline No. & Description & Material \\
\hline 1 & Power cylinder & Brass \\
\hline 2 & Cylinder plate & 6061 alloy \\
\hline 3 & Base plate & 6061 alloy \\
\hline 4 & Displacer guide & Brass \\
\hline 5 & Displacer cylinder & Brass \\
\hline 6 & Fly wheel & Brass \\
\hline 7 & Bearing plate & 6061 alloy \\
\hline 8 & Displacer fly wheel & Brass \\
\hline 9 & Power piston & Plain carbon steel \\
\hline 10 & Displacer & 6061 alloy \\
\hline 11 & Power piston spacer & Silicon \\
\hline 12 & Displacer rod & AISI 1020 \\
\hline 13 & Bearing axle & AIS 1020 \\
\hline 14 & Stainless steel washer & Stainless steel \\
\hline 15 & Connecting rod & 6061 alloy \\
\hline 16 & Connecting rod rear & 6061 alloy \\
\hline 17 & Connecting rod spacer & Brass \\
\hline
\end{tabular}

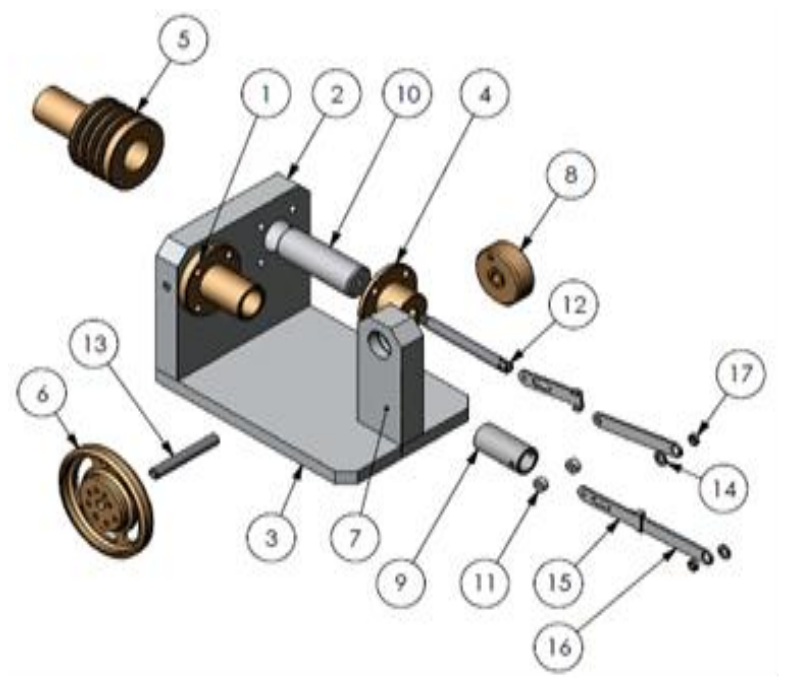

Fig. 4.Stirling engine parts fabricated and assembled by students in machine shop. 
Table 2: Results of student assessment

\begin{tabular}{|l|l|l|}
\hline \multicolumn{3}{|c|}{$\begin{array}{l}\text { Memorial University } \\
\text { Production Technology ENGI 3941 } \\
\text { December, 2012 }\end{array}$} \\
\hline \multicolumn{2}{|c|}{$\begin{array}{l}\text { Please read the following statement and use scale } \\
\text { from 1(strongly disagree) to 5 (strongly agree) to } \\
\text { evaluate your experience with teaching and learning } \\
\text { techniques and students learning }\end{array}$} \\
\hline $\begin{array}{l}\text { The following variety of learning environments } \\
\text { were increased my interest, learn, understand } \\
\text { course better, expose me to real world engineering } \\
\text { problems and more enjoyable. }\end{array}$ & 4.9 \\
\hline 1 & $\begin{array}{l}\text { Machine shop helps me practice doing } \\
\text { machining, fabricate and assembly engine } \\
\text { parts }\end{array}$ & 4.6 \\
\hline 2 & $\begin{array}{l}\text { Discovery channel in classroom helps } \\
\text { me relate what I took in class with } \\
\text { engineering profession }\end{array}$ & 4.4 \\
\hline 3 & $\begin{array}{l}\text { Quizzes and assignments in class were } \\
\text { Valuable exercises helps me practicing } \\
\text { solving problem, design and create } \\
\text { questions to be candidate for midterm and } \\
\text { final. }\end{array}$ & $\begin{array}{l}\text { Group discussions were valuable because } \\
\text { exposed me to different perspectives. }\end{array}$ \\
\hline \multicolumn{2}{|c|}{4} \\
\hline
\end{tabular}

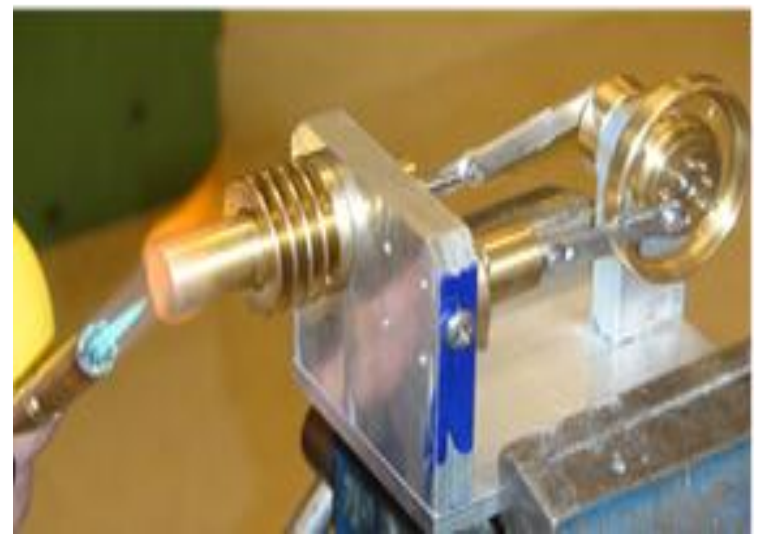

Fig. 5. Stirling engine operating continuously by a flame of a propane cylinder

\section{STUDENT ASSESSMENT}

This section examines the responses and assessments to student attitudes towards teaching and student learning. A voluntary and anonymous short questionnaire as shown in Table 2 was distributed in a Fall 2012 production technology class. There were 47 students in the class. The questionnaire was rated using a 1-5 scale and the average score for each question is shown in the last column. These results indicate a positive outcome on the student assessments of the teaching and learning methods.

\section{CONCLUSIONS}

For the course described in this paper, the instructor and students together became facilitators of the course material. The goal was to go beyond traditional teaching techniques, especially formal lecturing. Teaching and learning techniques and tools were introduced to expose students to real-world engineering problems and machine shop practice. The Discovery Channel videos presented some examples of real engineering problems and were effective in exposing student to some of the problems professionals can face. They enhanced the student sense of responsibility as they looked at issues that they may encounter, and increased the student confidence and competence in the course topic. The "hands-on" experience in the machine shop labs made students aware of the challenges and skills required to turn a design into a working item.

An innovative learning tool was introduced in which students put themselves in place of the instructor by reading course material and then, in a group setting, deciding what would be important questions to ask in a midterm and final exam. Finally, by collating all the questions for each of the 20 groups, students developed a useful tool for themselves for reviewing the salient facts and nomenclature of Production Technology. The variety of teaching tools used in this course engaged students in different styles of learning and, thereby increased the learning and retention of material.

\section{Acknowledgements}

Financial support from the Natural Sciences and Engineering Research Council of Canada (NSERC) is gratefully acknowledged.

\section{References}

[1] Sitnikova, Elena and Cropley, H. David, "Teaching and Learning in Engineering Education: Constructive Alignment", Conference Paper Proceedings: 4th ASEE/AAEE Global Colloquium on Engineering Education. Sydney, pp. 1-19, Australia 26, September 2005. \{ISBN; 1-8649-9828-8\}.

URL:http://arrow.unisa.edu.au:8081/1959.8/27485.

[2] Silverman, K. Linda and Felder M. Richard, 1988, "Learning and Teaching Styles in Engineering Education North Carolina State University“ Journal of Engineering Education, vol. 78, no. 7, pp. 674-681 1988.

[3] Brent Rebecca and Felder, M. Richard, "Understanding Student Differences", Journal of Engineering Education, pp. 57-72, 1994. 
\{Doi: 10.1002/j.2168-9830.2005.tb00829x

[4] Dewey John, "Experience and Education" Book 1st Touchstone New York: Simon and Schuster, 1938.

[5] Felder, M, Richard, "Reaching the Second Tier: Learning and Teaching Styles in College Science Education." Journal College Science Teaching, vol. 23, no 5, pp.286-290, 1993.

[6] Bigg John Burville, "Teaching for Quality Learning at University: What the Student Does Society for Research into Higher Education", The Society for Research into Higher Education, 1999. \{ISBN 0335201725, 9780335201723 \}

[7] Bruner S. Jerome, "Actual Minds, Possible Worlds the Jerusalem-Harvard Lectures" Publisher Harvard University Press, pp. 215, 1986. \{ISBN0674003667, 9780674003668\}

[8] Brooks, Jacqueline Grennon, "Teachers and Students: Constructivists Forging New Connections", Journal of Educational Leadership, vol. 47, no. 5, pp. 68-71 February, 1990.

[9] Fosnot C. Twomey, "Constructivism: A Psychological Theory of Learning. In C. T. Fosnot (Ed.), Constructivism: Theory, Perspectives, and Practice New York, Teachers College Press, Columbia University. pp. 8-33, 1996.
[10] Simon A. Herbert, "What We Know About Learning" American Society for Engineering Education, Journal of Engineering Education, vol. 87, no. 4, pp. 343-348, October 1998.

\{DOI: 10.1002/j.2168-9830.1998.tb00363x \}

[11] Kolb A. David, "Experiential Learning: Experience as the Source of Learning and Development", Prentice Hall, Englewood Cliffs, New Jersey, 1984.

URL:http://www.learningfromexperience.com/images/ uploads/process-of-experiential-learning.pdf

[12] Tagg, John and Barr, B. Robert, "From Teaching to Learning: A New Paradigm for Undergraduate Education", Change, vol.27, no. 6. 1995.

[13] Stice, E. James, "Using Kolb's Learning Cycle to Improve Student Learning" Journal of Engineering, vol. 77, no. 5, pp. 291-96, Feb 1987.

[14] Johnson W. David, Johnson T. Roger, and Smith A. Karl, "Active Learning: Cooperation in the College Classroom" School of Education and Human Development, George Washington University, 1991. \{ISBN: 1878380095, 9781878380098\} 